\title{
Trace element budgets in Lake Baikal question the dominant effect of salinity in estuarine removal processes
}

\author{
TIM JESPER SUHRHOFF', JÖRG RICKLI', ELENA G. \\ VOLOGINA', VIET PHAM ${ }^{3}$, MOUSTAFA BELHADJ', \\ EUGENE V. SKLYAROV ${ }^{2}$, CATHERINE JEANDEL $^{3}$, AND \\ DEREK VANCE' \\ Institute of Geochemistry and Petrology, ETH Zurich, 8092 \\ Zurich, Switzerland *jesper.suhrhoff@erdw.ethz.ch \\ ${ }_{2}^{2}$ Institute of the Earth's Crust, Siberian Branch of the RAS, \\ Irkutsk, 664033, Russia \\ ${ }^{3}$ LEGOS, Université de Toulouse, 31400 Toulouse, France
}

Removal of riverine trace elements from solution is well known for marine estuaries, resulting in dramatically lower concentration in seawater for elements like Fe, Mn, REEs, Al, and $\mathrm{Be}$ compared to rivers. Traditionally, this is often attributed to salinity induced coagulation and removal of colloidal matter and associated particle reactive elements'.

Although Lake Baikal has a lower ionic strength than its tributaries, a similar drop in concentration from riverine values is observed for many of the same elements (like Fe, Mn, REEs, $\mathrm{Al}, \mathrm{Be}, \mathrm{Cu}, \mathrm{Y})$. Based on comparable $\mathrm{Ce}$ anomalies of lake surface waters and tributaries, the drop in concentration at the river-lake interface is mostly due to adsorption of solutes onto existing particulates. REE concentrations (as well as $\mathrm{Fe}, \mathrm{Mn}$, $\mathrm{Be})$ in the lake also decrease with depth while Ce anomalies get more negative, indicating the ad-/absorption of REEs by newly formed authigenic FeMn phases ${ }^{2}$. The resulting short residence time of $\mathrm{Nd}$ in the lake leads to a non-uniform distribution of $\mathrm{Nd}$ isotopes. In contrast, $\mathrm{Sr}$ concentrations are similar in lake and rivers and $\mathrm{Sr}$ isotopes show a uniform distribution within the lake.

The controlling parameter for the drop in concentrations of these trace elements across the river-lake interface appears to be $\mathrm{pH}$, which is elevated in the lake (8.3-8.5 at the lake surface) compared to riverine values ( 7.8 , flow weighted average). This finding is consistent with observed correlations between $\mathrm{pH}$ and the concentrations of some of these elements in river waters $^{3}$. Together, these results call into question our understanding of the processes occurring in marine estuaries. Possibly, $\mathrm{pH}$ rather than salinity is also the dominant driver in the marine context.

1. Sholkovitz GCA 40, 831-845 (1976).

2. Bau GCA 63, 67-77 (1999).

3. Gaillardet et al. ToG 2. edit 7, 195-235 (2014). 